\title{
MEASURING THE EFFICIENCY OF APPLYING PASSIVE DESIGN STRATEGIES TO A RESIDENTIALPROTOTYPE IN EGYPT
}

\author{
Shymaa Hamdy El Sayed*1 Zainab Mohammad Al-Razaz ${ }^{1}$, Mohammad Yasser Lotfy ${ }^{1}$ and \\ Hussam El-Din Mohamed Bakr² \\ ${ }^{1}$ Department of Architectural Engineering Faculty of Engineering, Mataria, Helwan \\ University.airo, Egypt. \\ ${ }^{2}$ Department of Architectural Engineering BUE University.El-Shuruq, Cairo. \\ *Corresponding Author E-mail:Shymaa_waly@yahoo.com
}

\begin{abstract}
:
The residential buildings sector in Egypt is one of the largest sectors that consume electricity, which shows the extent of the need to balance the energy consumed and achieve thermal comfort for users. The research problem lies in the fact that the design of residential buildings does not take sufficiently into account energy saving considerations due to the complexity of environmental control calculations and the study of climate treatments in the design stage, which made residential buildings not achieve thermal comfort for the users and thus leads to dependence on various mechanical means that are economically costly and consuming nonrenewable energy And polluting the environment greatly.So, the study aims to evaluate the negative strategies and treatments used to improve energy consumption efficiency in residential buildings to reach the maximum possible savings in energy consumption without affecting the thermal comfort of users, and to apply these strategies to a housing project in Cairo, and to study their impact on the chosen residential model with the help of By one of the simulation programs used to evaluate the thermal performance of buildings, Design Builder Program. The final results of the study achieved a total saving of energy consumption estimated at about $29.3 \%$ of the total energy consumed annually.
\end{abstract}

KEYWORDS: Passive Design Strategies, Energy Saving, Social Housing Prototype, Processing the outer shell, Design Builder Program.

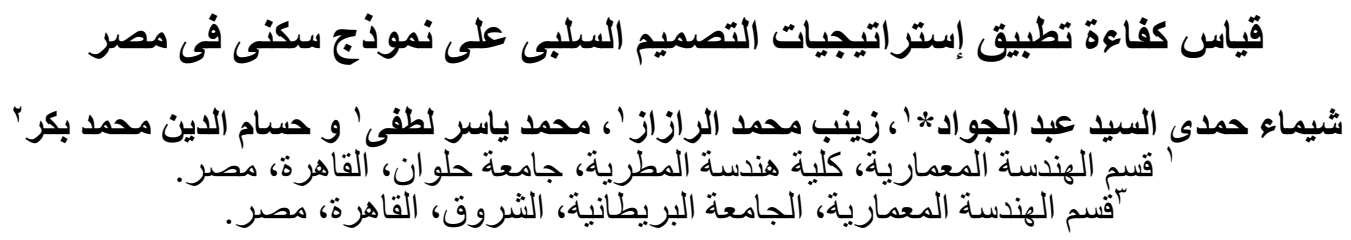

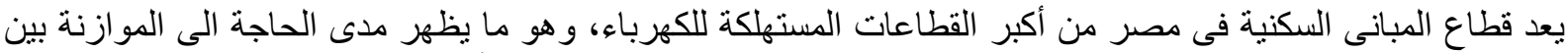

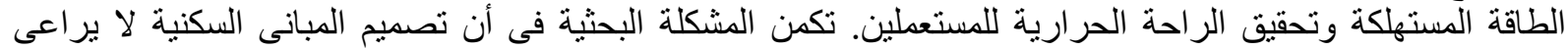

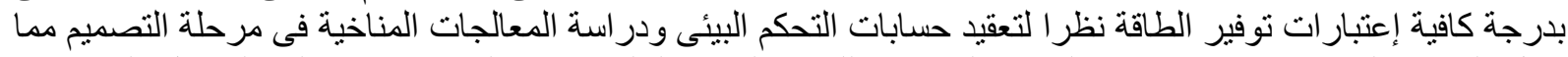

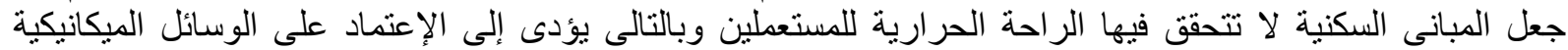

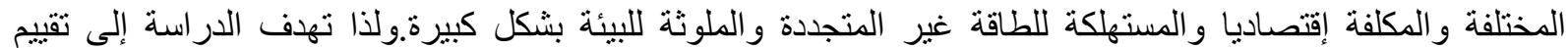
الإستر اتيجيات و المعالجات السلبية المستخدمة فتحسين كفاءة إستهلاك الطاقة فى المبانى السكنية للوصول إلى أقصى وفر 
MEASURING THE EFFICIENCY OF APPLYING PASSIVE DESIGN STRATEGIES TO A RESIDENTIALPROTOTYPE IN EGYPT

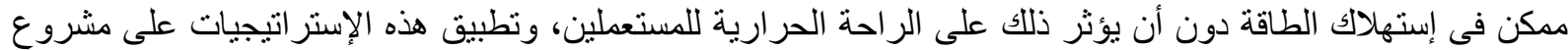

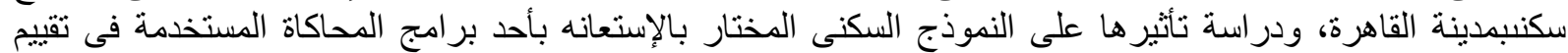

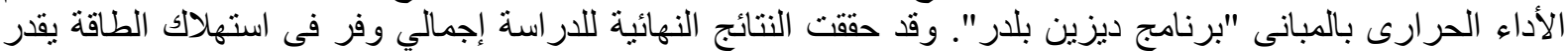

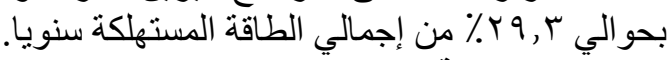

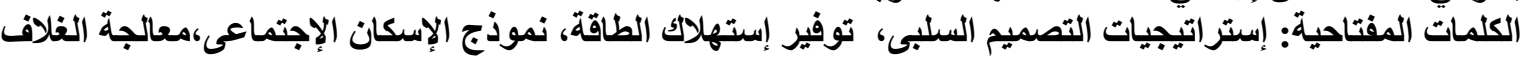
الخارجى، برنامج ديزين بلاتر.

مقدمة:-

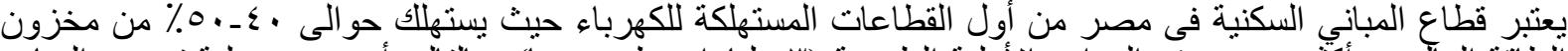

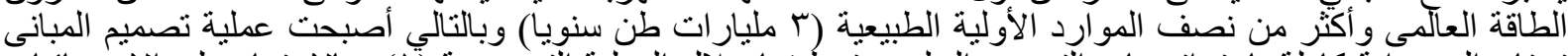

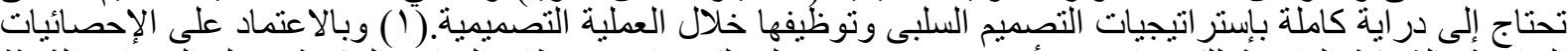

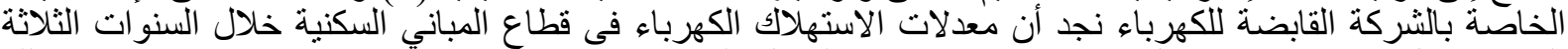

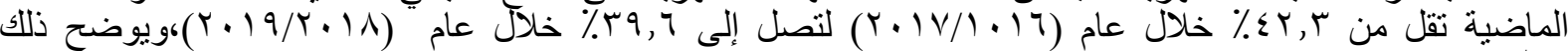

شكل(1). (1).
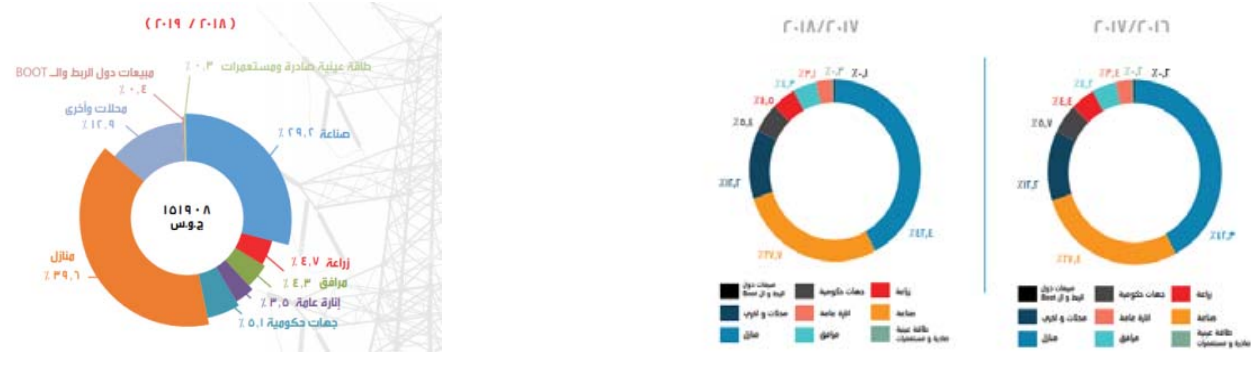

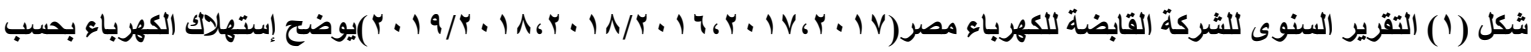
القطاعات

ولتحقيق هذا الهدف المحدد من توفير الطاقة في المبانى السكنية وتحقيق الراحة الحرارية لابد من التعامل مع المبنى على التى التهاء

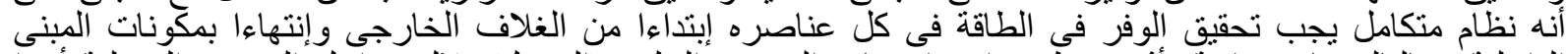

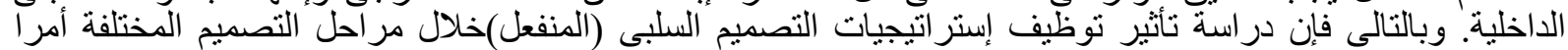

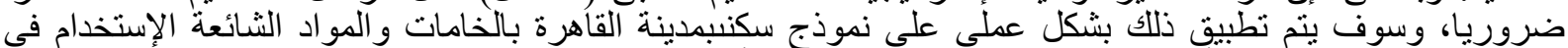

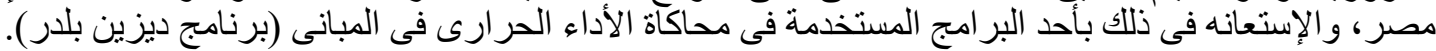

هدف البحث:

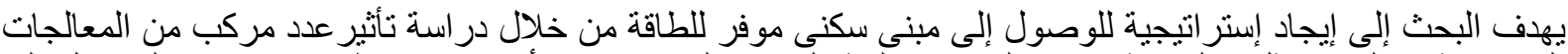

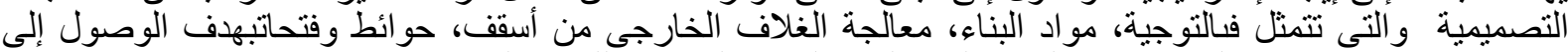
تصميم وحدة سكنية تحقق الموازنة بين الطاقة المستهلكة و الر احة الحر ارية للمستعملين.

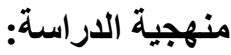

لتحقيق الهذف الرئيسي من البحث فإن الدر اسة البحثية تعتمد على المنهجية الآتية:

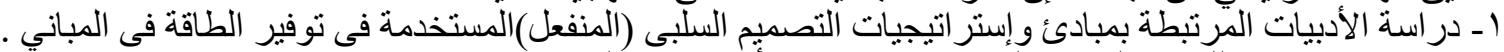

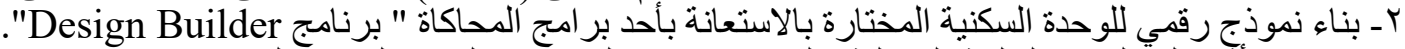

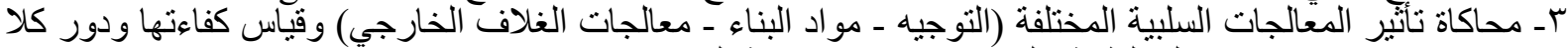
منها فى خفض معدلات استهلاك الطاقة على نموذج سكنى بمدينة القاهرة.

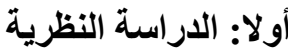

1/ تعريف التصميم السلبي (المنفعل):

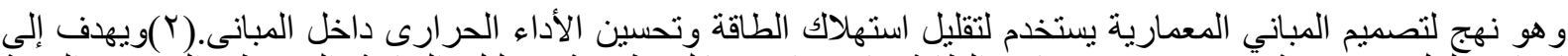

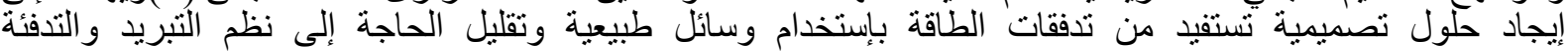


MEASURING THE EFFICIENCY OF APPLYING PASSIVE DESIGN STRATEGIES TO A RESIDENTIALPROTOTYPE IN EGYPT

الميكانيكية(r)، ويمكن تنفيذ نهج التصميم السلبى لأقصى حد ممكن لخفض إستهلاك الطاقة فى المبانى من خلال تطبيق

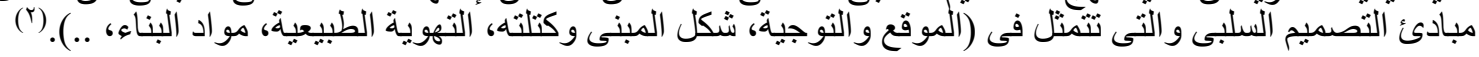

r / مبادئ و إستراتيجيات التصميم السلبى المستخدمه لتوفير إستهلاك الطاقة فى المبانى السكنية:-

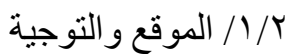

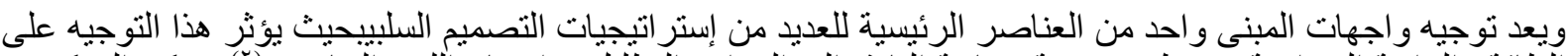

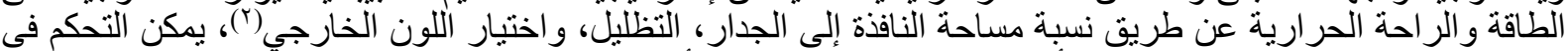

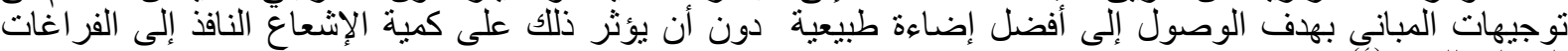

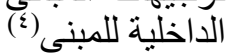

r/ شكل المبنى وكتلتة

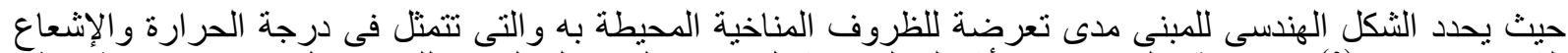

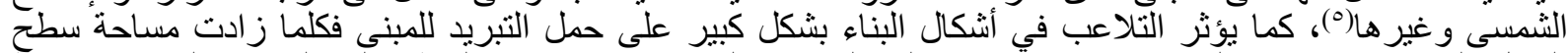

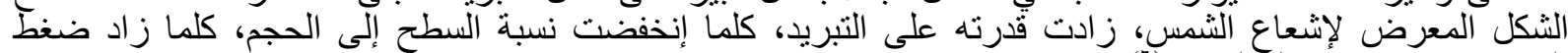

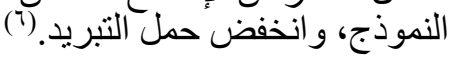

T/ مو اد البناء

حيث تتعرض المبانى لأشعة الثمس الحارة فى فصل الصيف مما يشكل عبئً على السكان بسبب الحر ارة النافذة إلى الداخل

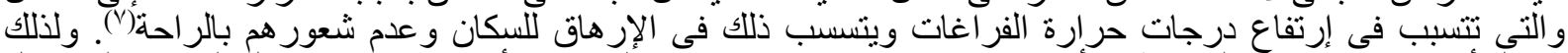

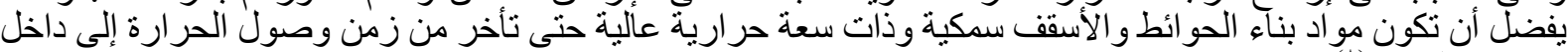

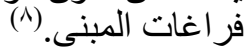

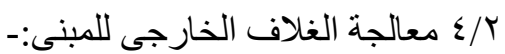

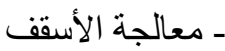

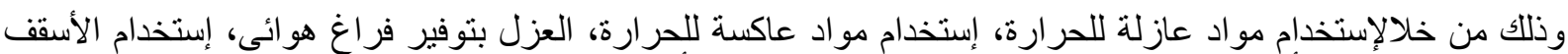

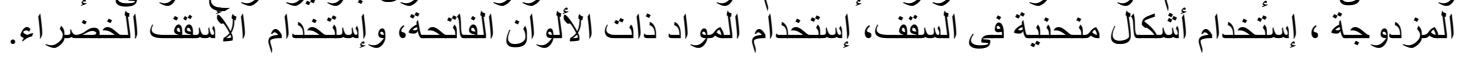

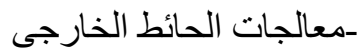

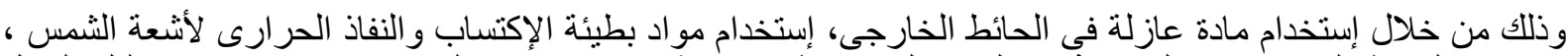

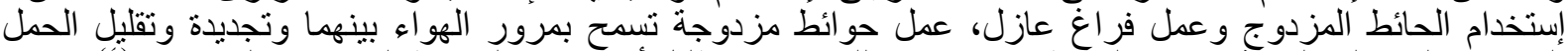

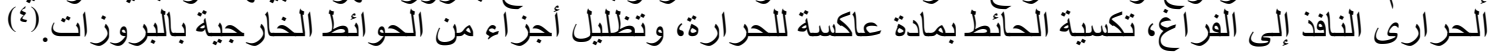

- تصميم الفتحات

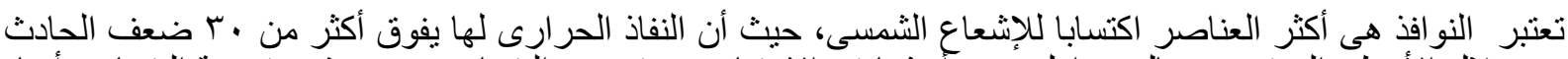

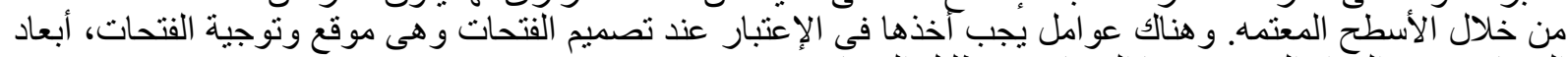

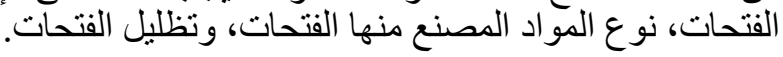

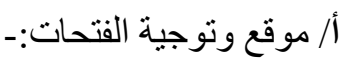

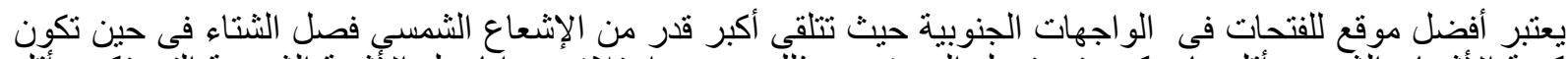

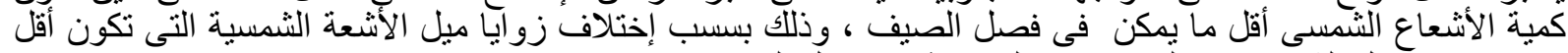
مايمكن فى فصل الثتاء وتزيد التقترب من العمودية فى فصل فل الصيف.

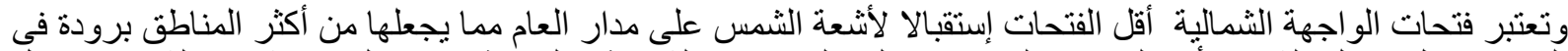

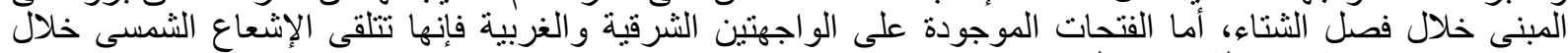
فترات محددة عند شروق الثمس وقبل غروبها.

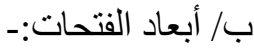


MEASURING THE EFFICIENCY OF APPLYING PASSIVE DESIGN STRATEGIES TO A RESIDENTIALPROTOTYPE IN EGYPT

تساهم مساحة الفتحات بصورة كبير ة في كمية الإشعاع الثمسى النافذ إلى فر اغات المبنى، ولذللك يجب مر اعاة تصميمها

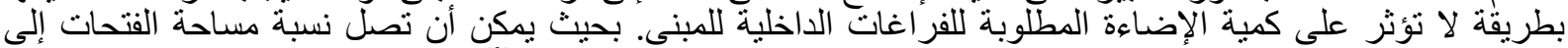

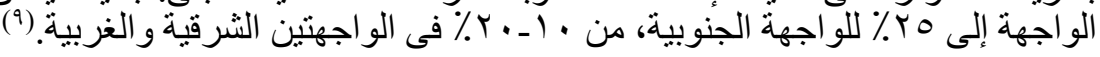
ج/ نوع المو اد المصنع منها الفتحات:-

يؤثر نوع الزجاج المستخدم فى الفتحات على معدل دخول الإشعاع الثمسى إلى داخل فر اغات المبنى، وتختلف نسبة نفاذية الأشعة الثنمسية خلال زجاج الفنحات وفقات لعدة عو امل مثل:زاوية سقوط الأشعة الثمسية، نوع مادة الزجاج المستخدم فى الفتحات وسمكه، و عدد الأسطح الزجاجية للفتحات.

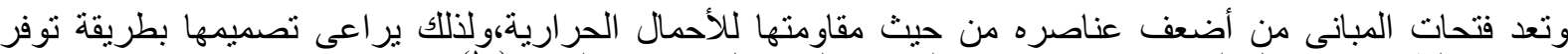

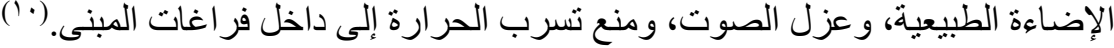

د/ تظليل الفتحات:

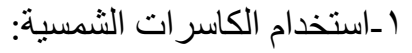

تهدف كاسر ات الثمس إلى منع الإشعاع الثمسى فى الأوقات الغير مرغوب فيها فى فصل الصيف ، التقليل قدر الإمكان

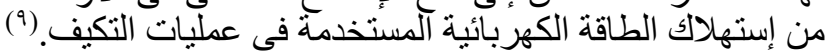
الكاسرات الأفقية :تكون أكثر فاعلية على نو افذ الواجهة الجنوبية حيث تمنع دخول الإشعاع الثمسى خصوصا فى فصل الصيف،وذذلك لأن ز اوية إرتفاع الثمس تكون كبئ كبيرة فى هذة الفترة.

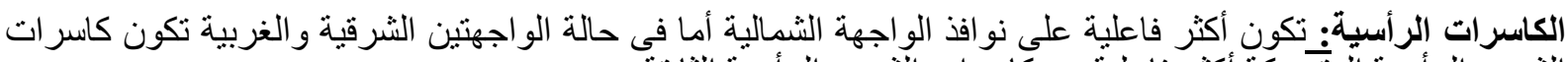

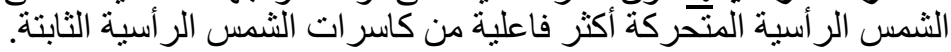

كاسرات الثمس المركبة: يمكن إستخدامها لتظليل نو افذ الواجهة الجنوبية.وتستخدم على الواجهتين الثرقية و الغربية فى الثى

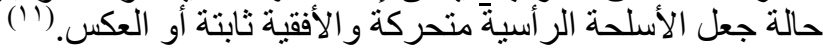

كاسرات الثمس المتحركة أتوماتيكيا :يستخدم هذا النظام بواسطة التحكم بماتور كهربائيا أوتوماتيكى وتكون فعالة حيث

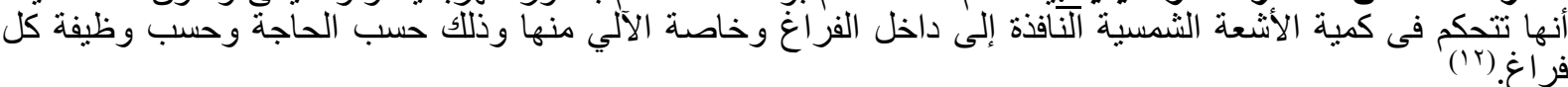

ثانيا: الاراسة التطبيقية

$$
\text { / / وصف النموذج: }
$$

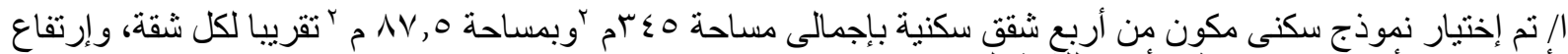
(أرضى + ع أدوار)، بمتوسط هـ أفر اد اللثقة الو احدة.

ب/ إفتقاد النموذج للوسائل و المعالجات التصميمة التى تساعد على خفض معدلات الطاقة المستهلكة دون أن يأثر ذلك على الر أحة الحر ارية للمستعملين.

بر/ إجريت عملية الدحاكاة بالدور الأخيربالكامل للنموذج نظر الكونة أكثر الأدوار عرضه للإشعاع الثمسى المباشرمعظم أوقات النهار ،وكذلك العو امل المناجية الأخرى.

ويوضح شكل ( () مسقط أفقى لللور المتكررلنموذج السكنى المختار. 


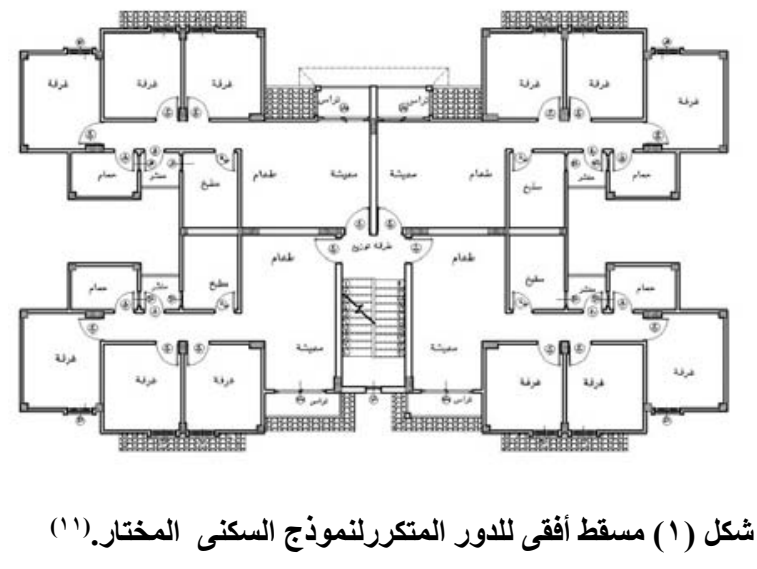

ץحاكاة الأداء الحرارى للنموذج بدون معالجات:-

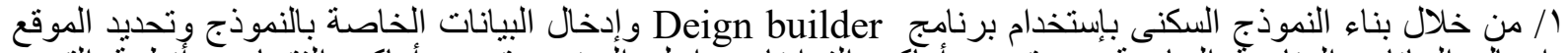

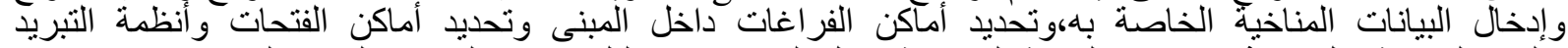

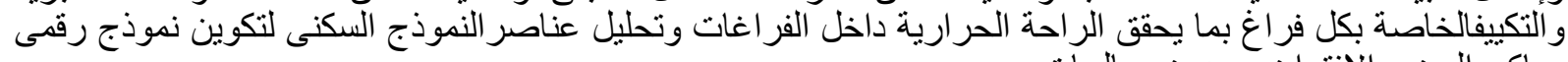
يحاكى الوضع الإفتر اضى بذون معالجات. r/درجة الحر ارة المطلوبة عند تشغيل وحدات التكييف : ضبط درجة الحرارة عند مبهس. r/ الحوائط الداخلية و الخارجية من الطوب الطفلى المفرغ وبسمك ب اسم. ع / السقف الخر سانى بسمك 0 اسم وبدون عازل حرارى.

0 - تم إدخال البيانات المناخية الخاصة بمدينة القاهرة. ץ/ رصد نتائج التحليل المناخى لنموذج السكنى بإستخدام برنامج Design builder للحالة المرجعية بدون معالجات:/ / معدلات إستهلاك الطاقة الكهربائية على مدار العام:-

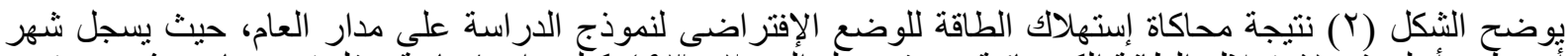

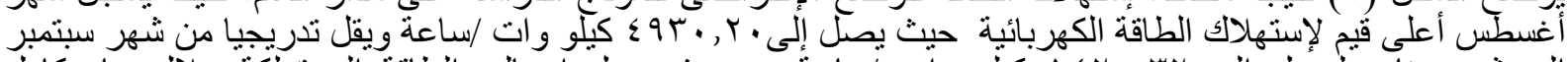

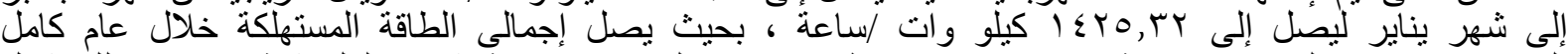
إلى إلى

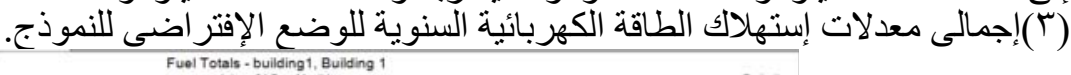

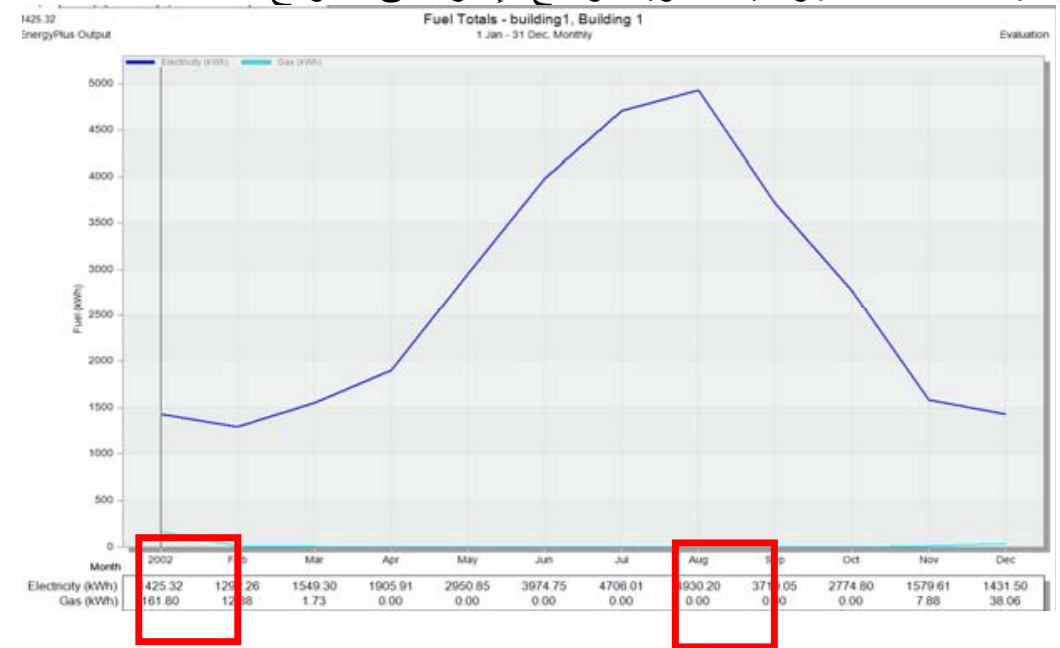

شكل (ץ) يبن معدلات إستهلاك الطاقة الكهربائية على مدار العام للوضع الإفتراضى"مدينة القاهرة" 


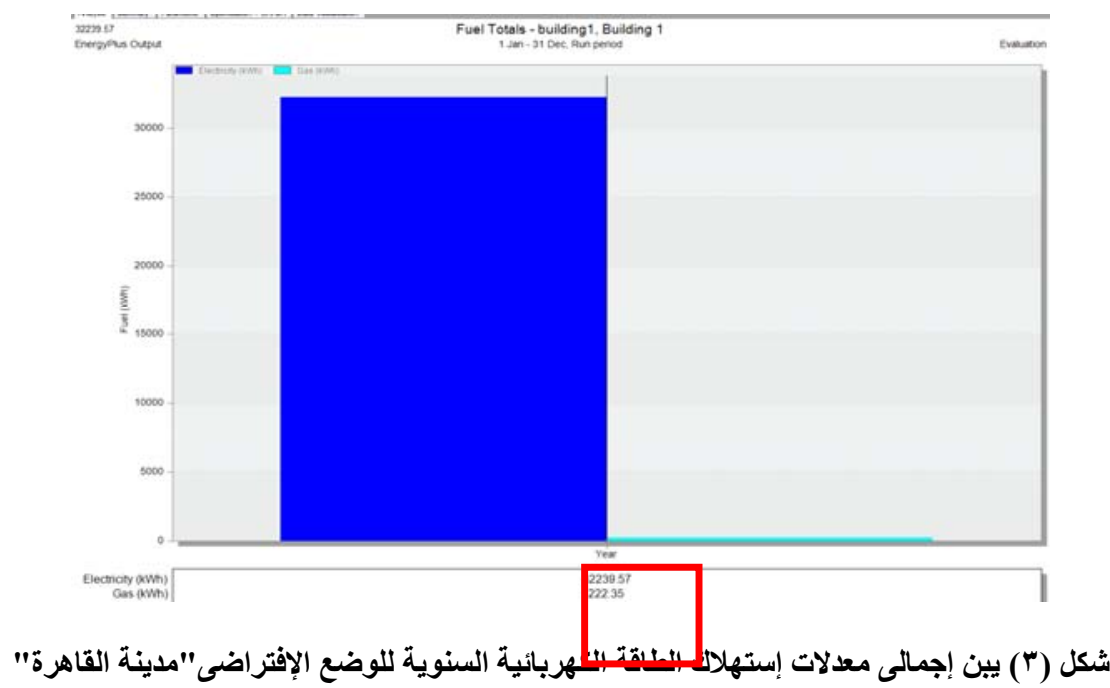

ء/دراسة تأثير تطبيق بعض مبادئ التصميم السلبى على الأداء الحرارى داخل فراغات النموذج السكنى :-

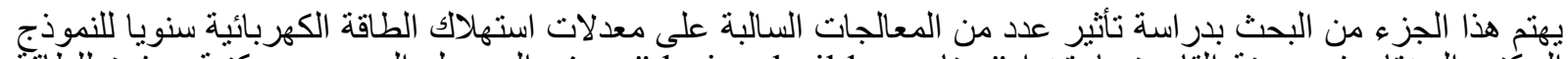

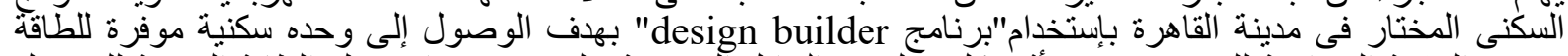

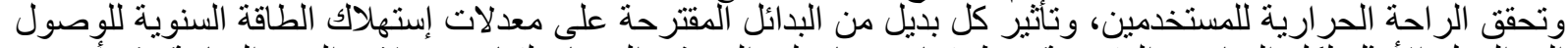

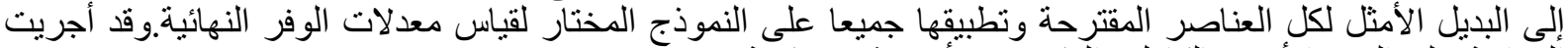

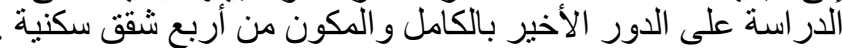

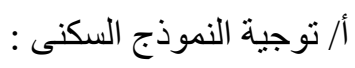

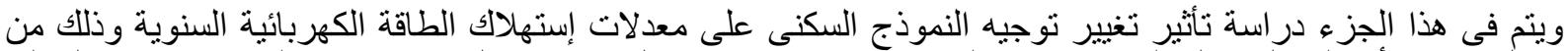

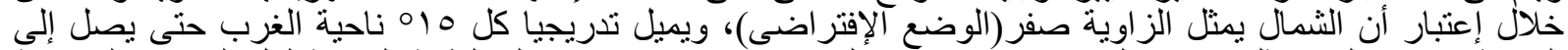

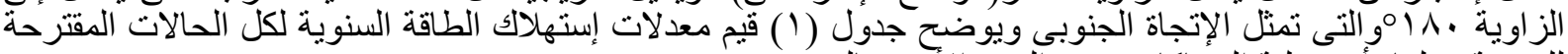

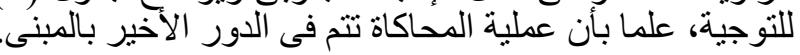


جدول ( ) قيم معدلات إستهلاك الطاقة السنوية لكل البذائل التصميمية المقترحة للتوجية:-

\begin{tabular}{|c|c|}
\hline \multicolumn{2}{|c|}{ البذائل التصميمية المقترحة } \\
\hline \multicolumn{2}{|c|}{ أ أ توجية النموذج السكنى } \\
\hline إجمالى معدلات إستهلاك الطاقة السنوية لتحقيق & 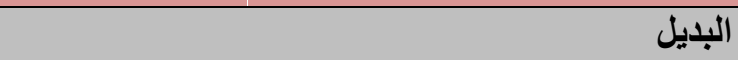 \\
\hline 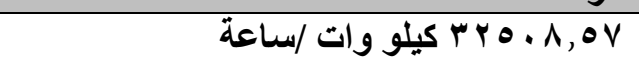 & البديل الأولِ: الميل بزاوية ه ا×عن الوضع القائم \\
\hline 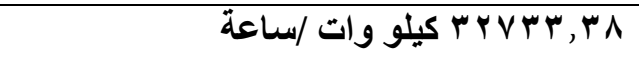 & البديل الثانى:الميل بزاوية ، ــ عن الوضع القائم \\
\hline 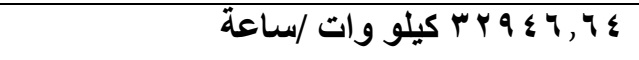 & البديل الثالث:الميل بزاوية ه ؛ عن الوضع القائم \\
\hline 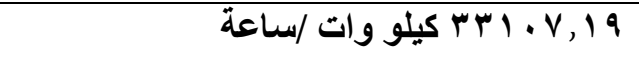 & 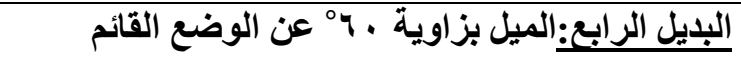 \\
\hline 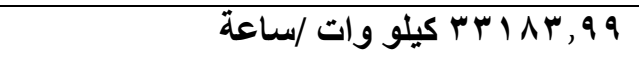 & البديل الخامس:الميل بزاوية ه Vo عن الوضع القائم \\
\hline ل & البديل السادس: الميل بزاوية ، وْ عن الوضع القائم \\
\hline 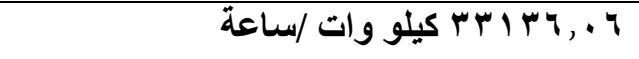 & البديل السابع:الميل بزاوية هـ ـ ـ عن الوضع القائم \\
\hline 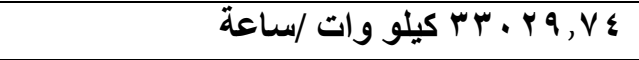 & البديل الثامن: الميل بزاوية ـ ب ا× عن الوضع القائم \\
\hline ا & البديل التاسع:الميل بزاوية هـ إْ عن الوضع القائم \\
\hline 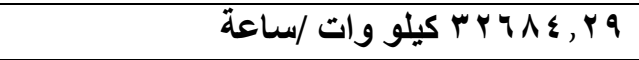 & البديل العاشر:الميل بزاوية ، ـ > عن الوضع القائم \\
\hline 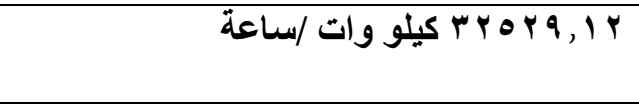 & القائم الحيل الحادي عشر:الميل بزاوية ه 17 أعن الوضع \\
\hline 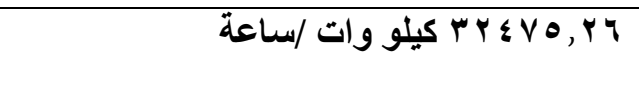 & 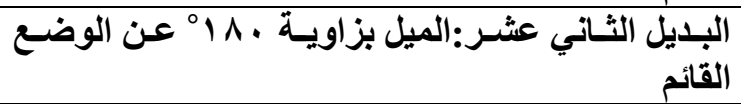 \\
\hline
\end{tabular}

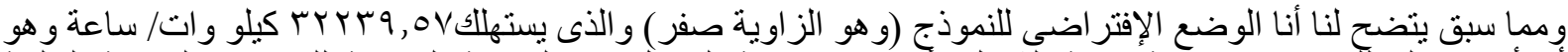

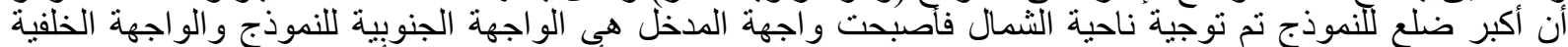

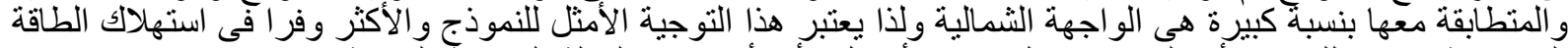

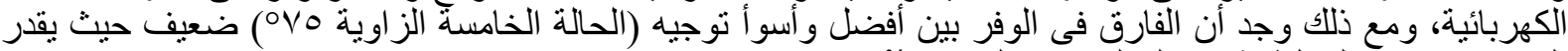

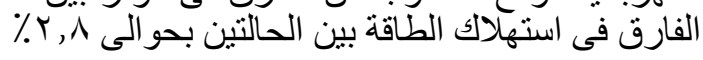

ب/ مو اد البناء المستخدمة:

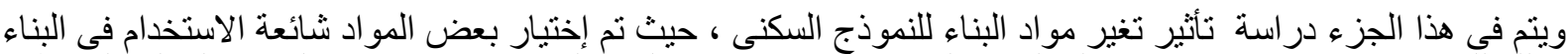

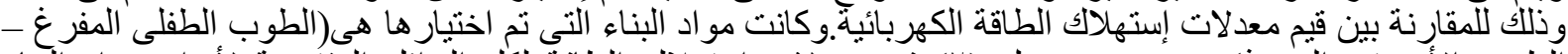

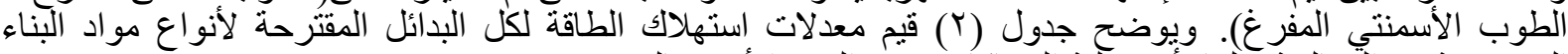
المستخدمة فى المعالجة، علما بأن عملية المحاكاة تتم فى الدور الأخير بالمبنى.

جدول (r) قيم معدلات إستهلاك الطاقة لكل البدائل المقترحة لأنواع مواد البناء المستخدمة فى المعالجة:-

\begin{tabular}{|c|c|}
\hline & البدائل التصميمية المقترحة \\
\hline & ب/ مواد البناء المستخدمة \\
\hline الطاقة السنوية معدلات إستُهلاك الراحة & البلايل \\
\hline & 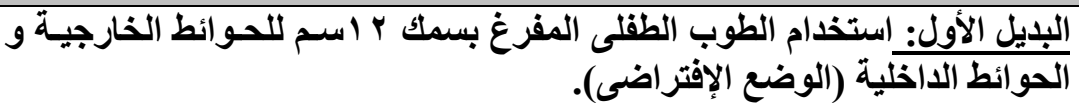 \\
\hline إساعة & 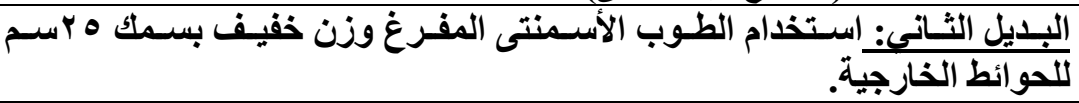 \\
\hline 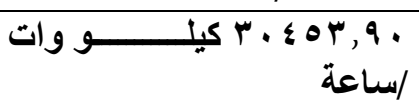 & البديل الثالث:استخدام الطوب الطقلى المفرغ بسمك ه ب سم للحوائط الخارجية. \\
\hline
\end{tabular}


ومما سبق بتضح لنا أن استخدام الطوب الأسمنتى المفرغ وزن خفيف بسمك هب اسم للحو ائط الخارجية هو الأفضل من حيث الطيث

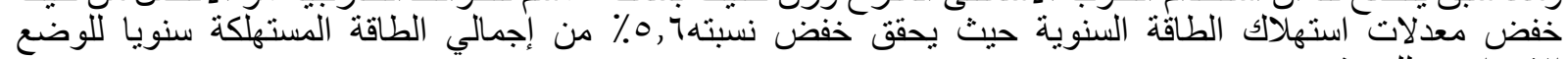
الإفتر اضى للنموذج.

$$
\text { ج/ / معالجة الغلاف الخارجى للمبنى: }
$$

• ويتم فى هذا الجزء در اسة تأثير استخدام مو اد عازلة للحر ارة فى الأسقف مثل مادة البوليسترين بسمك هسم.

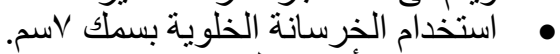

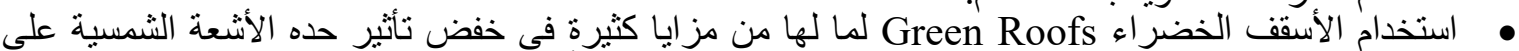

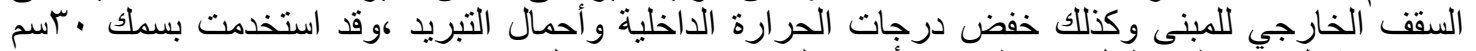

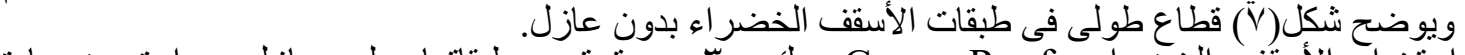

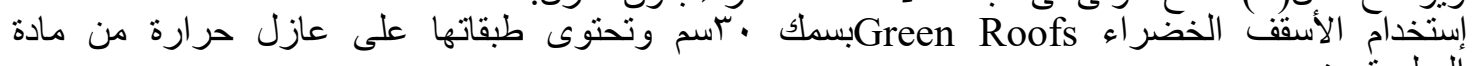
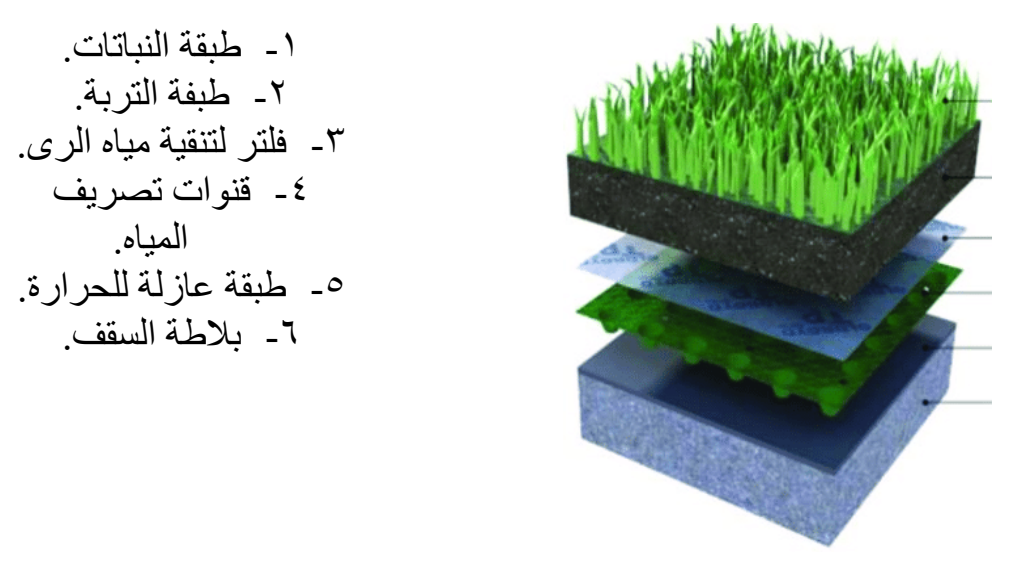

شكل(\&) قُطاع طولى يوضح طبقات الأسطح الخضر اء(بدون

عازل حرارى). (^) ألبوليسترين

در اسة تأثثر إستخدام حائط مزدوج من الطوب الطفلى المفرغ، الطوب الأسمنتى المفر غ بسمك بأسم اسم لكل حائط

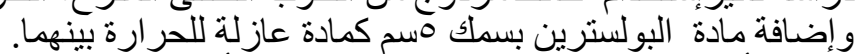

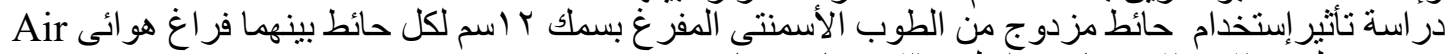

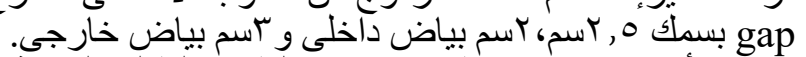

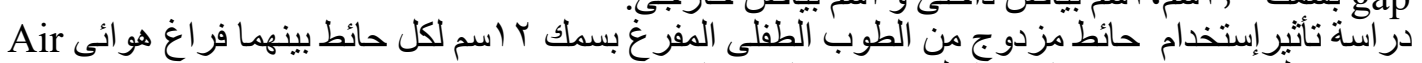

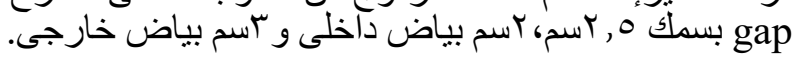

$$
\text { r/ معالجة الفتحات الخارجية (النو افذ والفتحات) }
$$

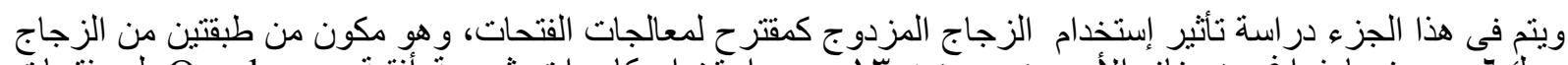

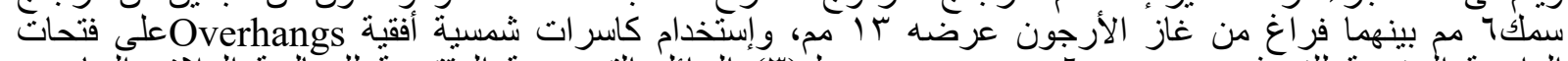

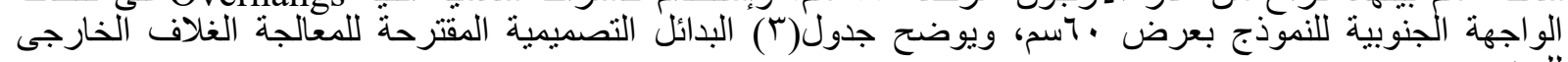


جدول (r) الحلول التصميمية المقترحة لمعالجة الغلاف الخارجى للمبنى.

\begin{tabular}{|c|c|}
\hline \multicolumn{2}{|l|}{ البدائل التصميمية المقترحة } \\
\hline \multicolumn{2}{|l|}{ ج/ معالجة الغلاف الخارجى للإموذج } \\
\hline البديل & 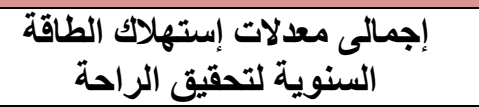 \\
\hline \multicolumn{2}{|l|}{ / / معالجة الأسقف } \\
\hline 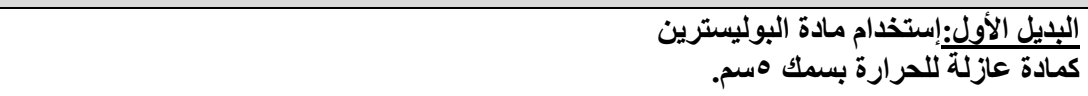 & 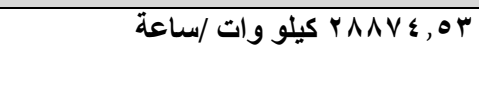 \\
\hline البديل الثاني:إستخدام الخرسانة الخلوية بسمك Vسم. & 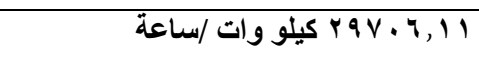 \\
\hline البديل الثالث:استخدام الأسطح الخضر اعبدون عازل حرارى. & 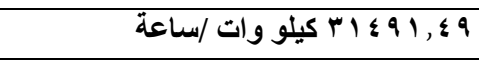 \\
\hline البديل الرابع:إستخدام الأسطح الخضر اء ومادة البوليسترين كعازل حرارى للسقف. & 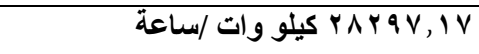 \\
\hline & ب/ / معالجة الحوائط الخارجية \\
\hline 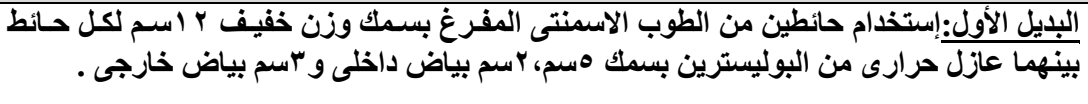 & 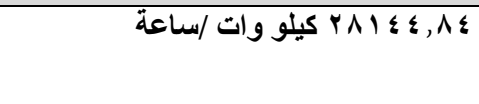 \\
\hline 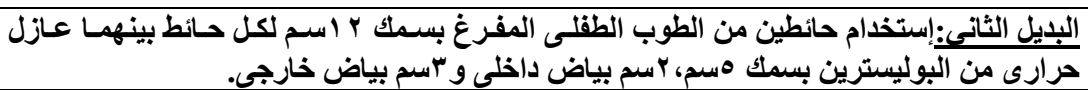 & 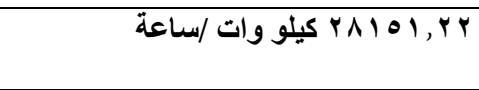 \\
\hline 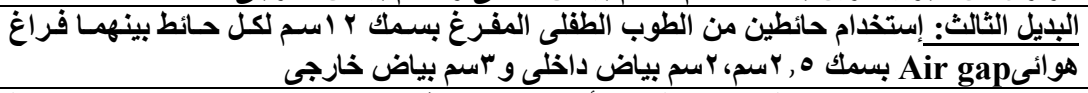 & 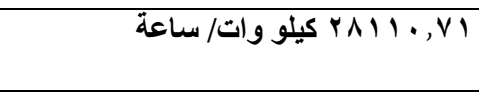 \\
\hline 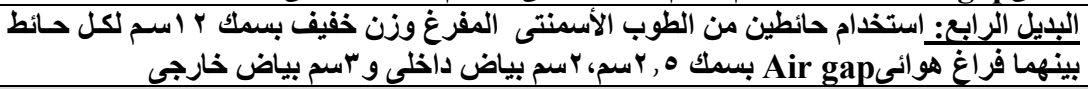 & 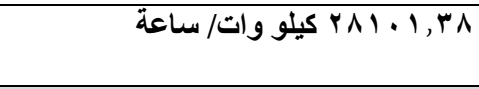 \\
\hline \multicolumn{2}{|c|}{ r/ معالجة القتحات الخارجية (النوافذ والفتحات) } \\
\hline 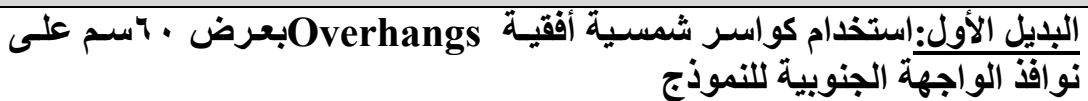 & 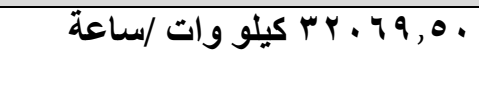 \\
\hline 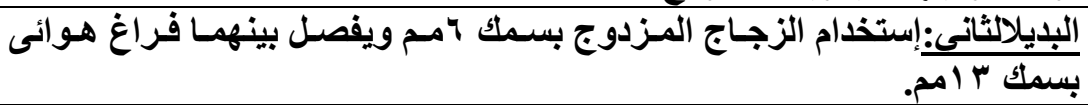 & 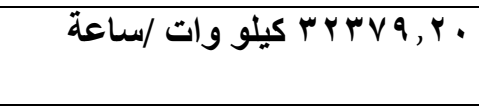 \\
\hline
\end{tabular}

ه/مقارنة بين المعالجات المختلفة وتوضيح المعالجات الأكثر والأقل أهمية من حيث خفض إستهلاك الطاقة(نسب (الخفض):- (0) 
جدول(ء)مقارنة بين المعالجات المختلفة وتوضيح المعالجات الأكثروالأقل أهمية من حيث خفض إستهلاك الطاقة.

\begin{tabular}{|c|c|c|c|c|}
\hline خفض المعات الأقل أهمية من حيث الطاقة & 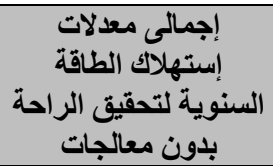 & أهم المعالجات المستخدمة منض إستهلك الطاقة & 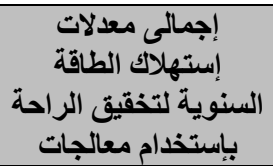 & الفزق في المعالجات الوفر \\
\hline \multicolumn{5}{|c|}{ البدائل المستخذمة أ/ توجية النموذج السكنى } \\
\hline البليل الخامس: زاوية هV×. & 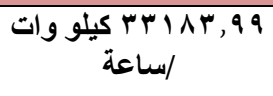 & 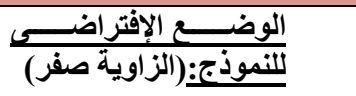 & 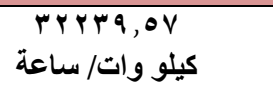 & $\% r, q$ \\
\hline \multicolumn{5}{|c|}{ ب/ مواد البناء المستخذمة } \\
\hline 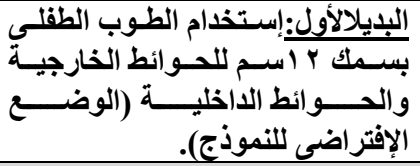 & 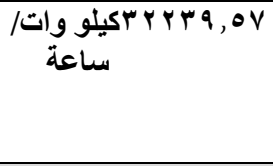 & 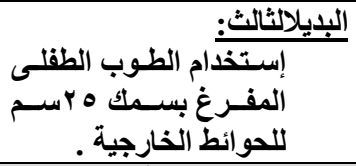 & 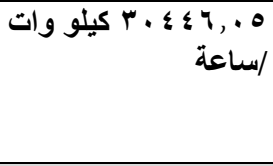 & $\% 0,7$ \\
\hline \multicolumn{5}{|c|}{ ج/معالجة الغلاف الذارجى للنموذجة الأسقف } \\
\hline 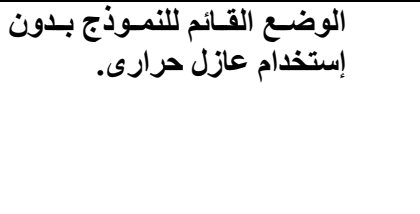 & 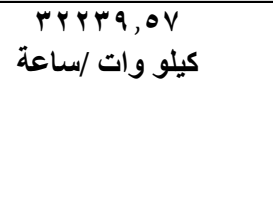 & 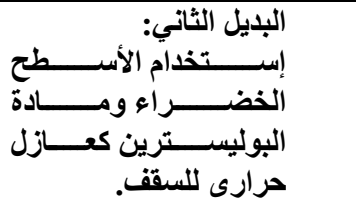 & 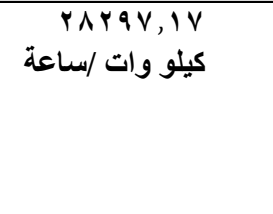 & $\% \backslash r, r$ \\
\hline \multicolumn{5}{|c|}{ l r / معالجة الحوائط الخارجية } \\
\hline 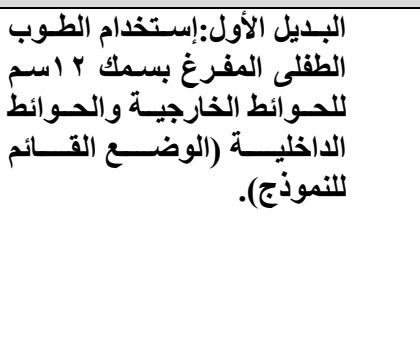 & 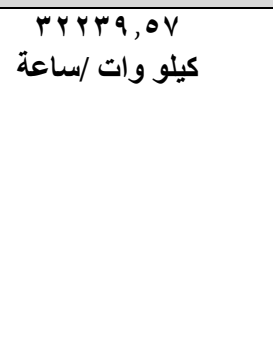 & 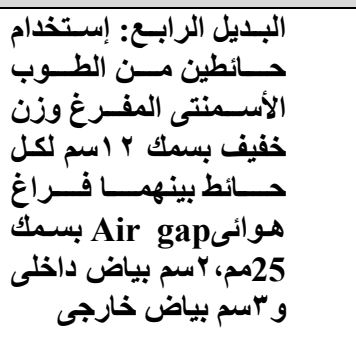 & 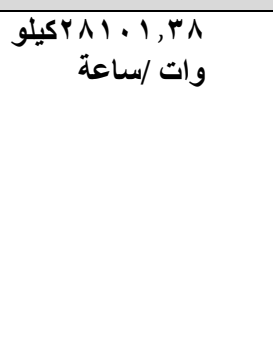 & $\% \backslash r, \wedge$ \\
\hline \multicolumn{5}{|c|}{ r/ / معالجة الفتحات الخارجية (النوافذ والفتحات) } \\
\hline 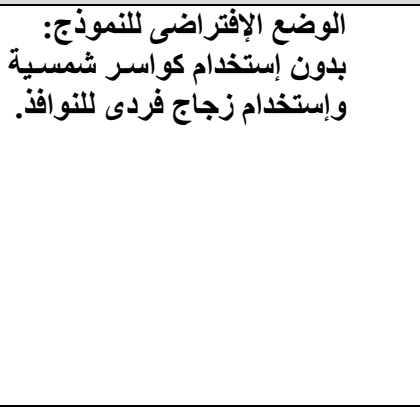 & 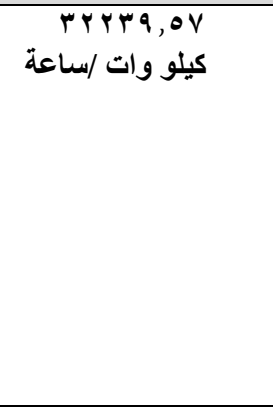 & 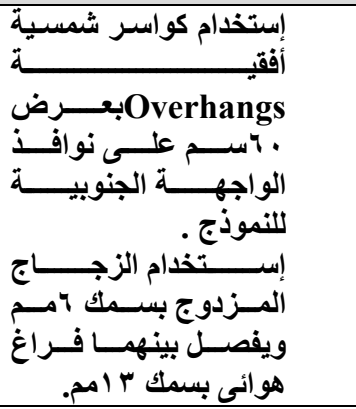 & 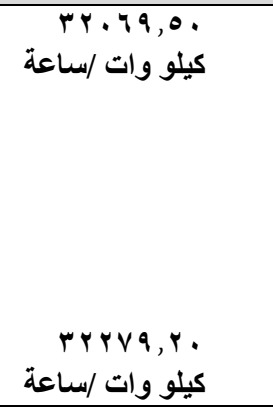 & $\% \cdot, \bullet$ \\
\hline
\end{tabular}

ومما سبق ينضح مدى كفاءة تطبيق إستر اتيجيات التصميم السلبى ودور ها فى خفض معدلات إستهلاك الطاقة الكهربائية

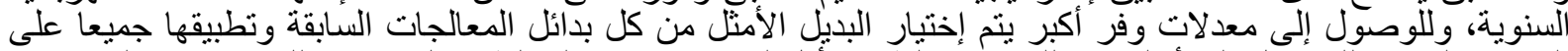

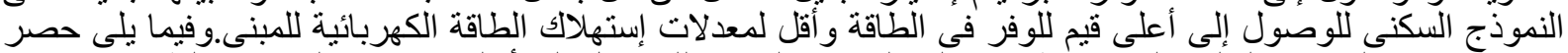

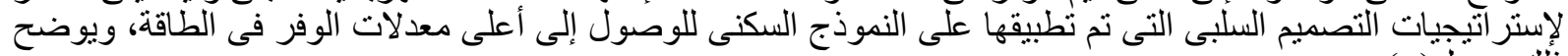

ذللك جدول(0). 
جدول(ه) إستراتيجيات التصميم السلبى التى تم تطبيقها على النموذج السكنى للوصول إلى أعلى معلات الوفرفى الطاقة

\begin{tabular}{|c|c|c|}
\hline السنوية لتحقيت إستهلاك الطاقة & البليل & المستخدمة إتيجيات التصـــــــيم \\
\hline 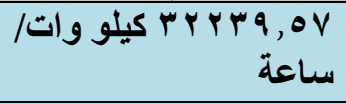 & صفر الوضع القائم الإفتراضى للنموذج و هو الزاوية & أ/ توجية النموذج السكنى \\
\hline 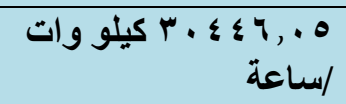 & 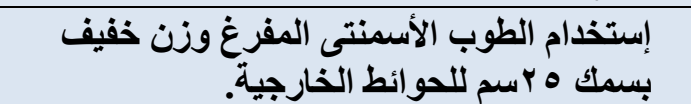 & ب/ مواد البناء المستخدمة \\
\hline $\begin{array}{r}\text { /ساعة } \\
\text { / Y Y Y V IV }\end{array}$ & 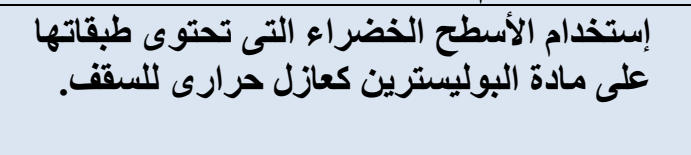 & للإذ/معالجة الغلاف الخارجى \\
\hline 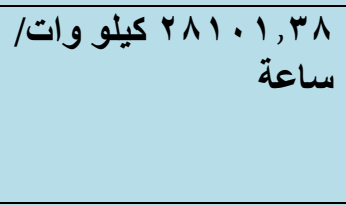 & 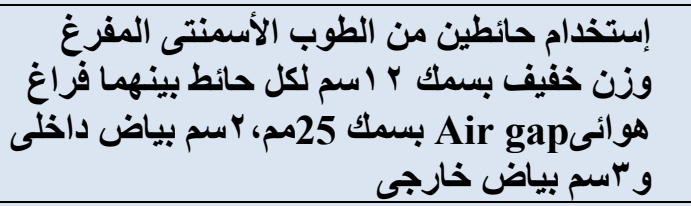 & الخ / معالجة الحوائط \\
\hline 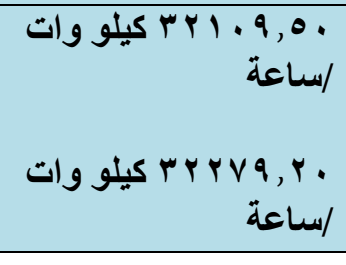 & 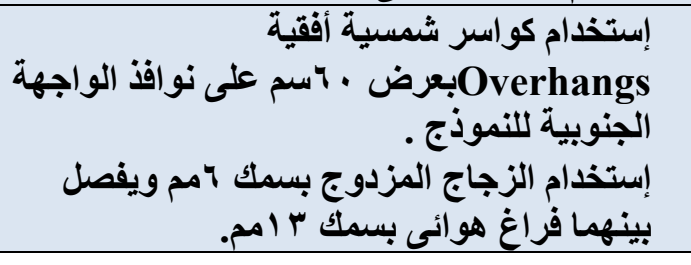 & 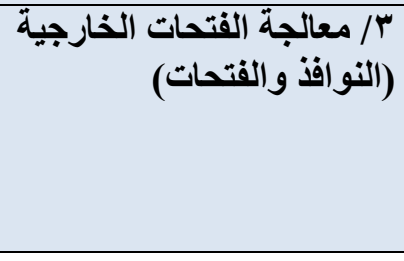 \\
\hline
\end{tabular}

آس/ آمناقشة لنتائج محاكاة الأداء الحرارى للنموذج بعد تطبيق أفضل الحلول السابقة و أكثر ها من حيث خفض معدلات

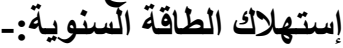

من خلال تطبيق أفضل البدائل التصميمية المقترحة إنخفض إجمالى الطاقة الكهربائية المستهلكة سنويا للاور

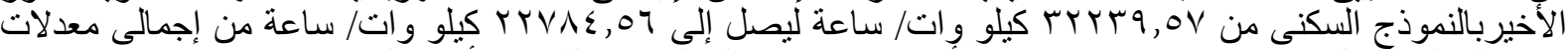

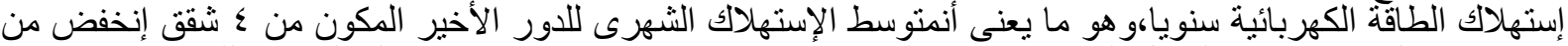

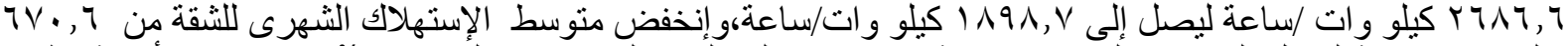

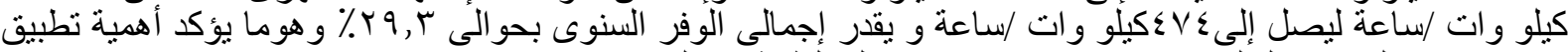
إستر اتيجيات التصميم السلبى ودور ها في خفض إتى إستهاتلك الطاقة في المبانى.

( النتائج

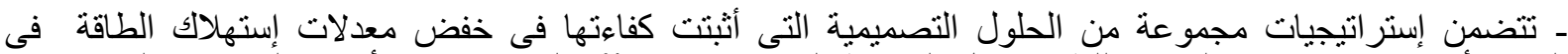

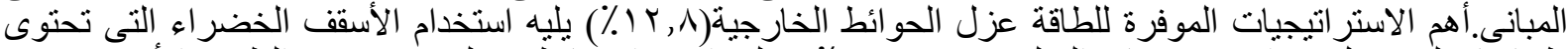

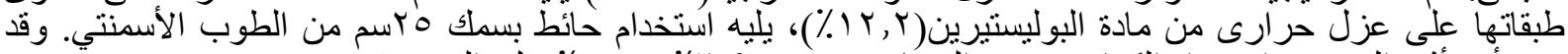

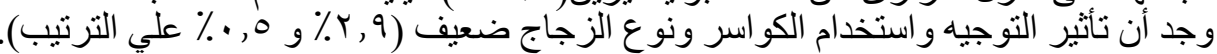

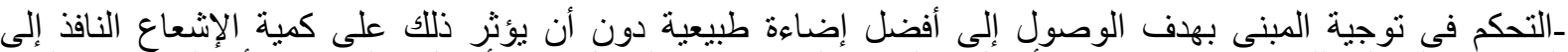

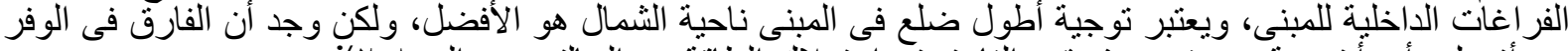

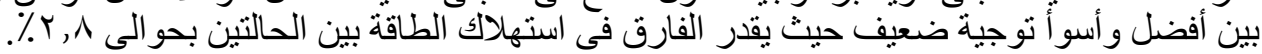

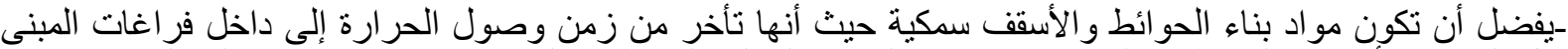

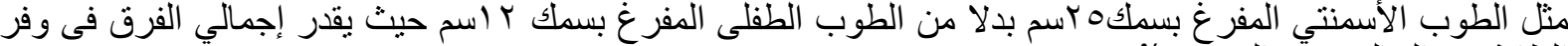

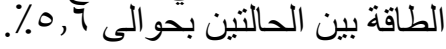

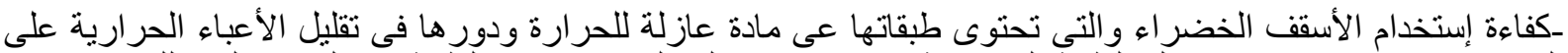

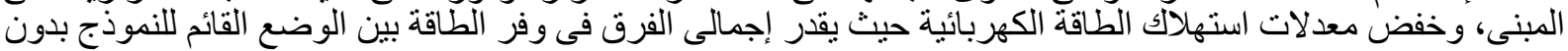


MEASURING THE EFFICIENCY OF APPLYING PASSIVE DESIGN STRATEGIES TO A RESIDENTIALPROTOTYPE IN EGYPT

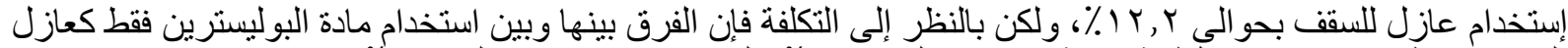

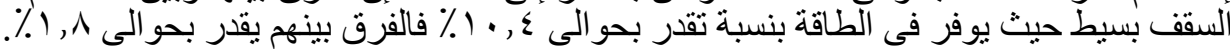

ـ كفاءة إستخدام العزل للحوائط الخارجية بإستخدام فراغ هو ائى حيث يعمل على الحماية من إنتقال الحرارة إلى داخل

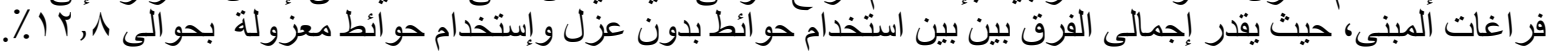

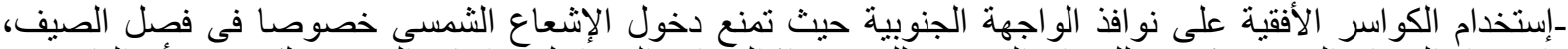

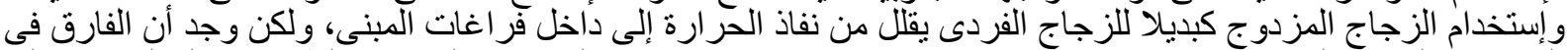

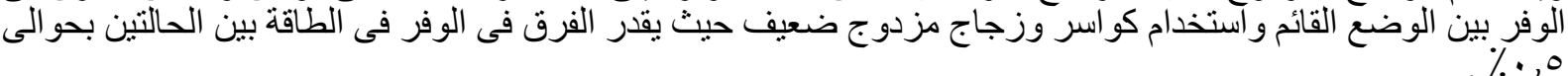

ـأهمية استخدام بر امج محاكاة الأداء الحرارى للمباني و التى تساعد المعمارى فى مقارنة عدة بدائل تصميمية تمكنة من الوصول إلى قرارت تصميمية سليمة.

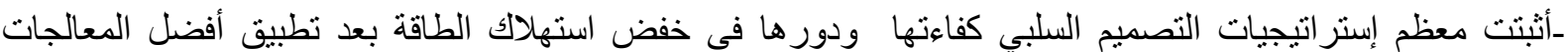

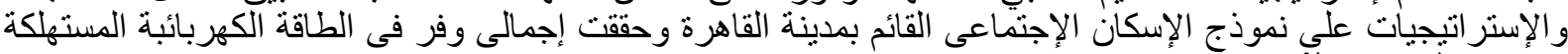

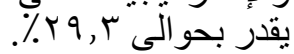

ـأنخفض متوسط الاستهلاك الثهري للطاقة الكهربائية لكل شقة من T ، • VT كيلو وات/ساعة ليصل إلى ع ع كيلو وات

0/ التوصيات

يوصي بالإعتماد علي نظم ومبادئ التصميم السلبى وتطبيقها على المبانى نظر الدور ها الكبير فى خفض معدلات إستهلاك الطاقة وتحقيق الر احة الحرارية للمستعملين.

يوصى بإستخدم العزل الحرارى للحو ائط الخارجية نظر الفاعليته فى خفض إستهلاك الطاقة.

يوصى باستخدام العازل الحرارى للأسقف حيث أنها أثنتت فاعليتها فى خفض معدلات الطاقة ويعتبر الفارق بسيط بالنظر إلى التكلفة بينها وبين استخدام الأسقف الخضر ألغاء.

أهمية توفير برامج محاكاة الأداء الحرارى وتدريب الدراسين عليها بهدف التعرف على سلوك المبنى وإختيار المعالجات المناسبة قبل الثروع فى تنفيذه.

المراجع

السلقينى، روضة، (V V • Y Yم):"العمارة التقليدية الثمسية كمنطلق لتحسين إستهلاك المبانى للطاقة"، ورقة بحثية،

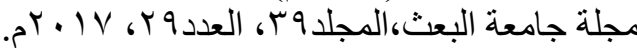

[2] .Cobalt EngineeringVladimir Mikler, MSc, P.Eng., LEED® AP,Albert Bicol, P.Eng., LEED ${ }^{\circledR}$ AP,BethBreisnes, Hughes Condon Marler : Architects

[3] Michel Labrie, MAIBC, MOAQ, MRAIC, LEED® AP(2009):Passive Design Toolkit, page 17.

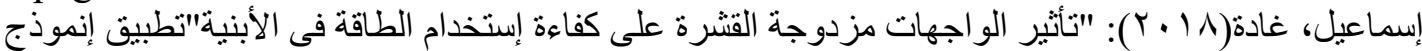

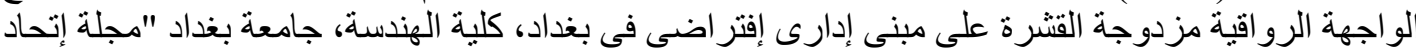

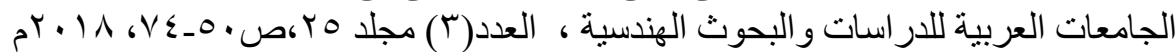

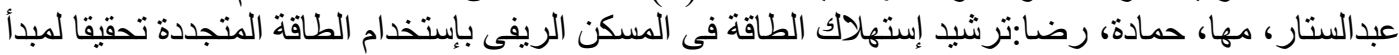

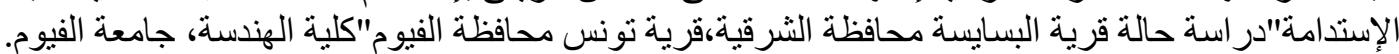

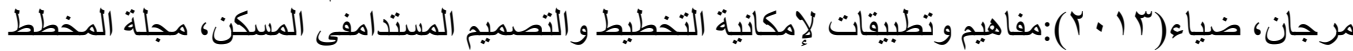

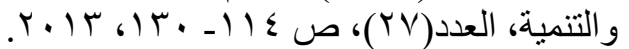

[7] .Wan Sharizatul Suraya W.M.Rashdi, Mohamed Rashid Embi: Analyzing Optimum Building Form in Relation to Lower Cooling load. 25-27 April 2015.

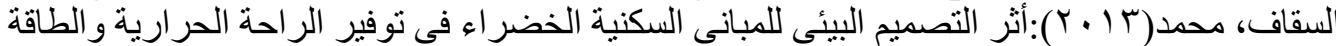

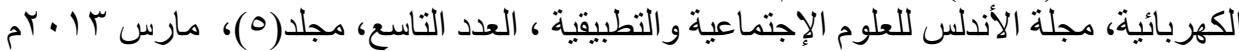


MEASURING THE EFFICIENCY OF APPLYING PASSIVE DESIGN STRATEGIES TO A RESIDENTIALPROTOTYPE IN EGYPT

محمد، أحمد( (1 + r م):إستخدام المحاكاة لتقييم وتحسين الأداء الحرارى للمبانى السكنية (در اسة حالة: مدينة

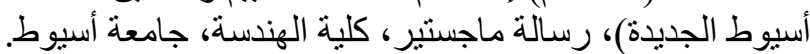

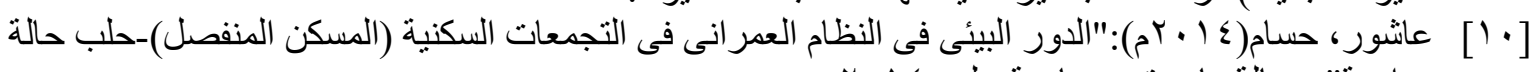

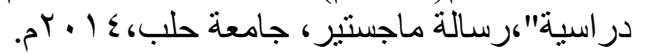

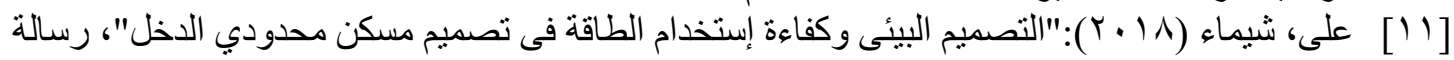

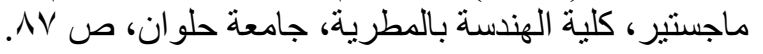

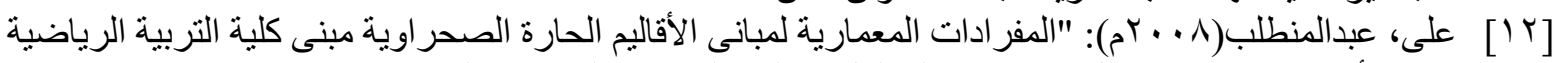

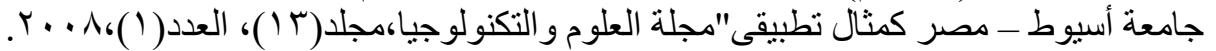

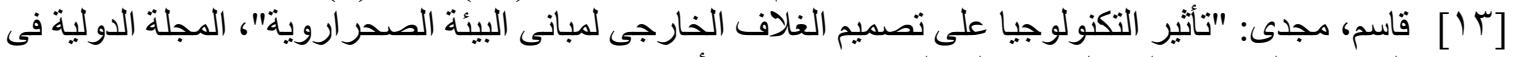
العمارة و الهندسة و التكنولوجيا، كلية الهندسة، جامعة الأز هر. 